\title{
Study of whole blood and T cell chimerism in monitoring HLA identical allogeneic hematopoietic transplantation
}

\begin{abstract}
Chimerism analysis is an important method for monitoring outcome of allogenic hematopoietic stem cell transplantation. Variable number tandem (VNTR) analysis is considered an informative technique to follow up chimerism state. The aim of the work is to study certain number of VNTRs to identify their potential value in the detection of chimerism in transplanted patients in conventional ablative transplants. Also to demonstrate the value of $\mathrm{T}$ cells subset analysis in detecting transplantation outcomes. This study included 17 pairs undergoing HSCT. Informative loci pre-transplantation using five VNTR loci and two gene loci were identified. After transplantation the informative loci were used to detect chimerism status. After DNA extraction from blood samples, amplification of VNTR loci was performed using a conventional PCR protocol. Extra sample post transplantation was collected and pre-treated with resetting technique in order to separate $\mathrm{T}$ cells, its product was subjected to DNA extraction then amplification of informative loci was done. Amplified product of DNA samples was run on $2 \%$ agarose gel stained using ethidium bromide. Fourteen recipients showed full done chimerism in both whole blood and $\mathrm{T}$ cells separated cells, one recipient died after HSCT, one recipient showed split chimerism and one pair failed to detect informative locus. VNTR analysis using a panel of five loci is suitable to detect state of chimerism after HSCT.
\end{abstract}

Keywords: VNTR, T cell, hematopoietic, chimerism, resetting
Volume 6 Issue 6 - 2018

\author{
Akram Deghady,' Manal Elsorady, ${ }^{2}$ Neveen \\ Lewis, ' Asmaa Nasreldine' \\ 'Departments of Clinical and Chemical Pathology, University of \\ Alexandria, Egypt \\ ${ }^{2}$ Department of Internal Medicine, University of Alexandria, \\ Egypt
}

Correspondence: Akram Deghady, Departments of Clinical and Chemical Pathology and Internal Medicine, Faculty of Medicine, University of Alexandria, Egypt,

Emailakran61@yahoo.com

Received: June 09, 2018 | Published: November 01, 2018

\section{Introduction}

Allogeneic hematopoietic stem cell transplantation (HSCT) is a potentially curative procedure for a variety of haematological malignant and non-malignant diseases. ${ }^{1,2}$ Successful outcome after allogeneic bone marrow transplantation has been correlated with a state of stable hematopoietic chimerism (full donor chimerism). ${ }^{3}$ In this context, chimerism analysis is an important method in monitoring post-hematopoietic stem cell transplantation outcomes.4-6 Many techniques have been used to detect chimerism statuses such as single-nucleotide polymorphism (SNP), short tandem repeats (STR), restriction fragment length polymorphism (RFLP) and variable number tandem repeats (VNTR). ${ }^{7,8}$ VNTR loci are groups of DNA sequences that represent a source of highly polymorphic markers for individual identification. ${ }^{8}$ They are repetitive DNA motifs with a core repeat length ranging from $10-100 \mathrm{bp} .^{9}$

Many advantages are known for VNTR analysis: the need of lower amount of DNA, easy and rapid processing protocol, no need for the use of restriction enzymes or the use of radioisotopes and more importantly, the overall cost is much lower than other techniques. ${ }^{8,10}$ The most frequently used material for chimerism analysis is peripheral blood and bone marrow. If chimerism is analysed within certain cellular fractions, e.g. T cells, B cells, or myeloid cells, the term 'subset chimerism' is commonly used. A 'complete donor chimerism' denotes the condition when all cells within a given compartment are derived from the donor, while mixed chimerism denotes a mixture of donor and recipient cells. If one compartment, e.g. the T cells, is completely of recipient origin, whereas the others are donor-derived, this is a situation of 'split chimerism'.., 11 The aim of the work is to study certain number of VNTR to identify their potential value in the detection of chimerism in conventional ablative transplanted patients. Also to demonstrate the value of T-cells subset analysis added to whole blood chimerism in detecting transplantation outcomes.

\section{Patients and methods}

The study was conducted at Alexandria University (MOASSAT Hospital) - Bone marrow transplantation unit during the period from June 2016 to February 2018. Seventeen patients and their donors were included. Patients were transplanted for malignant and non-malignant haematological diseases from HLA identical siblings. Twelve patients were transplanted for acute myeloid leukaemia, one for acute lymphoblastic leukaemia, two patients for aplastic anaemia, one for thalassemia and one for paroxysmal nocturnal haemoglobinuria. Six out of the seventeen patients were children and the rest were adults. The median duration of follow-up was six months. The patients were followed up according to the centre of International Blood and Bone Marrow Transplant Research (CIBMTR) guidelines. Three out of the seventeen patients died during the follow-up period, either due to relapse or severe infections. One patient developed acute graft versus host disease and five patients developed chronic graft versus host disease.

Peripheral blood samples were collected from both recipients and their HLA identical sibling prior to transplantation. A second peripheral blood sample was collected from the recipients on $28^{\text {th }}$ day after transplantation. The three samples were subjected to DNA extraction using $\mathrm{ABIO}$ pure $^{\mathrm{TM}}$ extraction, Cat No: M501DP100 USA. Another sample was collected from recipients on $28^{\text {th }}$ day after transplantation for its processing using Rosette Sep ${ }^{\mathrm{TM}}$ Human T Cell Enrichment Cocktail from Stem cell technologies, Cat No: 15021 USA then processed for DNA extraction. The concentration of DNA was estimated by UV spectrophotometry.

VNTR analysis was performed at Clinical Pathology Department, Faculty of Medicine, and Alexandria University. A panel of 5 VNTR 
loci (D1S80, D17 S30, YNZ-22Apo B and 33.6) and 2 gene loci (SRY and ZP3) was used. Amplification of these loci was performed as described in Tables $1 \& 2$. All reactions were performed in a volume of $25 \mu \mathrm{L}$ containing $13 \mu \mathrm{l}$ Thermo Scientific Dream Taq Green PCR
Master Mix (catalogue number: K1081), $1 \mu$ forward primer, $1 \mu 1$ reverse primer, $5 \mu 1$ RNase-free water and $5 \mu$ l template DNA followed by visualization in $2 \%$ ethidium bromide-stained gel.

Table I Representing VNTR sequences

\begin{tabular}{|c|c|c|}
\hline Primer & Sequence & Reference \\
\hline \multirow{2}{*}{ DIS80 } & Forward primer 5'-GAAACTGGCCTCCAAACACTGCCCGCCG & \multirow{2}{*}{26} \\
\hline & Reverse primer 5'-GTCTTGTTGGAGATGCACGTGCCCCTTGC & \\
\hline \multirow{2}{*}{ DI7S30 } & Forward primer 5'-CACAGTCTTTATTCTT- CAGCG-3' & \multirow{2}{*}{8} \\
\hline & Reverse primer5'-CGAAGAGTGAAGTGCACAGG-3' & \\
\hline \multirow{2}{*}{ YNZ22 } & Forward primer5' AAA CTG CAG AGA GAA AGG TCG AAG AGT GAA GTG & \multirow{2}{*}{27} \\
\hline & Reverse primer5' AAA GGA TCC CCC ACA TCC GCT CCC CAA GTT & \\
\hline \multirow{2}{*}{ Apo B } & Forward primer5'CCTTCTCACTTGGCAAATAC & \multirow{2}{*}{26} \\
\hline & Reverse primer5'ATGGAAACGGAGAAATTATG & \\
\hline \multirow{2}{*}{33.6} & Forward primer5'TGTGAGTAGAGGAGACCTCAC & \multirow{2}{*}{26} \\
\hline & Reverse primer5'AAAGACCACAGAGTGAGGAGC & \\
\hline \multirow{2}{*}{ SRY gene } & Forward primer5'CATGAACGCATTCATCGTGTGGTC & \multirow{2}{*}{8} \\
\hline & Reverse primer3'TTCTTAACGTCAAACGAAGGGCGTC & \\
\hline \multirow{2}{*}{ ZP3 gene } & Forward primer5'AGCCATCCTGAGACGTCCGTACA & \multirow{2}{*}{8} \\
\hline & Reverse primer3'TACCTGTGTCTTCTACACCAGTCC & \\
\hline
\end{tabular}

Table 2 Representing VNTR amplification protocols

\begin{tabular}{|c|c|c|c|c|c|c|c|}
\hline VNTR Locus & Initial denaturation & Denaturation & Annealing & Extension & Cycles & Final extension & Reference \\
\hline DIS80 & Imin at $94^{\circ} \mathrm{C}$ & Imin at $94^{\circ} \mathrm{C}$ & $I \min$ at $65^{\circ} \mathrm{C}$ & $5 \mathrm{~min}$ at $70^{\circ} \mathrm{C}$ & 28 cycle & $7 \min$ at $72^{\circ} \mathrm{C}$ & 28 \\
\hline DI7S30 & Imin at $95^{\circ} \mathrm{C}$ & Imin at $94^{\circ} \mathrm{C}$ & Imin at $55^{\circ} \mathrm{C}$ & $2 \mathrm{~min}$ at $72^{\circ} \mathrm{C}$ & 28 cycle & $7 \mathrm{~min}$ at $72^{\circ} \mathrm{C}$ & 8 \\
\hline YNZ 22 & Imin at $95^{\circ} \mathrm{C}$ & Imin at $95^{\circ} \mathrm{C}$ & $45 \mathrm{sec}$ at $60^{\circ} \mathrm{C}$ & Imin at $72^{\circ} \mathrm{C}$ & 30 cycle & $10 \mathrm{~min}$ at $72^{\circ} \mathrm{C}$ & 28 \\
\hline Apo B & $5 \mathrm{~min}$ at $94^{\circ} \mathrm{C}$ & Imin at $94^{\circ} \mathrm{C}$ & Imin at $58^{\circ} \mathrm{C}$ & $2 \min$ at $66^{\circ} \mathrm{C}$ & 30 cycle & $10 \mathrm{~min}$ at $72^{\circ} \mathrm{C}$ & 29 \\
\hline 33.6 & $2 \mathrm{~min}$ at $95^{\circ} \mathrm{C}$ & Imin at $95^{\circ} \mathrm{C}$ & Imin at $55^{\circ} \mathrm{C}$ & $1.5 \mathrm{~min}$ at $72^{\circ} \mathrm{C}$ & 35 cycle & $5 \mathrm{~min}$ at $72^{\circ} \mathrm{C}$ & 30 \\
\hline ZP3 gene & $5 \mathrm{~min}$ at $95^{\circ} \mathrm{C}$ & Imin at $95^{\circ} \mathrm{C}$ & $I \min$ at $60^{\circ} \mathrm{C}$ & $2 \min$ at $72^{\circ} \mathrm{C}$ & 35 cycle & $10 \mathrm{~min}$ at $72^{\circ} \mathrm{C}$ & 31 \\
\hline SRY/ ZP3 genes & Imin at $94^{\circ} \mathrm{C}$ & Imin at $94^{\circ} \mathrm{C}$ & $I \min$ at $65^{\circ} \mathrm{C}$ & $2 \mathrm{~min}$ at $72^{\circ} \mathrm{C}$ & 30 cycle & $10 \mathrm{~min}$ at $72^{\circ} \mathrm{C}$ & 8 \\
\hline SRY gene & $2 \mathrm{~min}$ at $94^{\circ} \mathrm{C}$ & $30 \mathrm{sec}$ at $94^{\circ} \mathrm{C}$ & $30 \mathrm{sec}$ at $57^{\circ} \mathrm{C}$ & Imin at $72^{\circ} \mathrm{C}$ & 35 cycle & $10 \mathrm{~min}$ at $72^{\circ} \mathrm{C}$ & 32 \\
\hline SRY gene & $1 \mathrm{Imin}$ at $95^{\circ} \mathrm{C}$ & Imin at $94^{\circ} \mathrm{C}$ & $45 \mathrm{sec}$ at $60^{\circ} \mathrm{C}$ & Imin at $72^{\circ} \mathrm{C}$ & 28 cycle & $60 \mathrm{~min}$ at $72^{\circ} \mathrm{C}$ & 33 \\
\hline SRY gene & $2 \mathrm{~min}$ at $94^{\circ} \mathrm{C}$ & $15 \mathrm{sec}$ at $94^{\circ} \mathrm{C}$ & $20 \mathrm{sec}$ at $65^{\circ} \mathrm{C}$ & $20 \mathrm{sec}$ at $72^{\circ} \mathrm{C}$ & 35 cycle & $10 \mathrm{~min}$ at $72^{\circ} \mathrm{C}$ & 34 \\
\hline
\end{tabular}

\section{Results}

In order to identify the informative VNTR for each donor and recipient pair, we prescreened a pre-transplantation recipient sample and a donor sample for our 5 VNTR loci. The VNTR is considered informative if there is an allelic difference between donor and recipient alleles.

In this study, out of 17 cases, D1S80 VNTR was found to be informative in 59\% of cases (10 cases), D17S30 and YNZ 22 VNTR were found to be informative in $47 \%$ of cases (8cases), Apo B VNTR was found to be informative in $41 \%$ of cases ( 7 cases) and 33.6 VNTR was found to be informative in $18 \%$ of cases ( 3 cases).

\section{Analysis of chimerism in post-transplantation samples showed}

Full donor chimerism could be detected in 14 cases (Figure 1). One case showed the persistence of recipient DNA chimerism which denoted the failure of implantation. This case was an acute myeloid leukaemia case that relapsed after transplantation and eventually died.

One case showed split chimerism in which whole blood chimerism post-transplantation showed full donor DNA chimerism while T cell separated cells showed recipient DNA chimerism. This case was a case B-Acute Lymphoblastic Leukaemia who showed positivity for minimal residual disease before transplantation (Figure 2).

In one case none of the analysed VNTR was found to be informative. We did not investigate further other VNTRs although we recommended the use a wider spectrum of VNTRs in this case or shifting to another method like STRs.

We were able to collect a follow-up sample for 4 patients after 4 months of transplantation. These cases showed earlier full donor chimerism and showed the persistence of full donor chimerism in the second follow up sample at 4 months. 


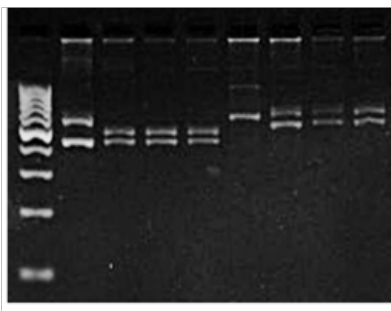

Lane 1: molecular marker (100 bp)

Lane 2: pre transplant pattern of case 17 for D1S80 VNTR

Lane 3: his donor pattern

Lane 4: represent the patient at day +28 (whole blood sample) showing only donor pattern indicating full donor chimerism

Lane 5: represent the patient at day +28 ( $\mathrm{T}$ cell separated sample ) showing only donor pattern indicating full donor chimerism

Lane 6: pre transplant pattern of case 16 for D1S80 VNTR

Lane 7: his donor pattern

Lane 8: represent the patient at day +28 (whole blood sample) showing only donor pattern indicating full donor chimerism

Lane 9: represent the patient at day +28 ( $\mathrm{T}$ cell separated sample ) showing only donor pattern indicating full donor chimerism

Figure I Full donor chimerism after transplantation.

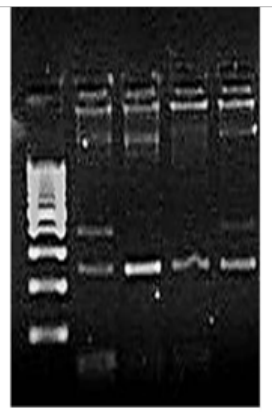

Lane 1: molecular marker (100 bp)

Lane 2: pre transplant pattern of case 15 for D17S30 VNTR

Lane 3: his donor pattern

Lane 4: represent the patient at day +28 (whole blood sample) showing only donor pattern

Lane 5: represent the patient at day +28 ( $\mathrm{T}$ cell separated sample ) showing recipient pattern indicating split chimerism

Figure 2 Full donor chimerism before transplantation.

\section{Discussion}

Selecting the most informative VNTR locus is the main key in chimerism analysis. ${ }^{3,12}$ In this study, we enrolled seventeen patients with their HLA identical siblings. We studied the potential value of various VNTR in the detection of chimerism status post-transplantation. We found that D1S80 VNTR was the most informative allele. D17S30 VNTR and YNZ22 VNTR showed similar discriminative power which is expected as D17S30 VNTR and YNZ 22VNTR are both located on chromosome $17 \mathrm{p} 13$. Scientists now are considering YNZ 22 VNTR as part of D17S30 VNTR. ${ }^{13,14}$ Apo B VNTR and 33.6 VNTR were informative to some extent.

Muniz et al. ${ }^{15}$ reported a frequency of $43 \%$ and $37 \%$ for D 17 S 30 and D1S80 respectively in their recipient-donor pairs while in our study it was $47 \%$ and $59 \%$ respectively ; whereas Stuppia et al. ${ }^{16}$ reported frequencies of $44 \%$ for APO-B and $25 \%$ for D1S80 compared to $41 \%$ for Apo B and $59 \%$ for D1S80 in our work. Considering Sreenan et al. $^{3}$ they reported a frequency of $69 \%$ for D1S $80,35 \%$ for D $17 \mathrm{~S} 30$, $11.5 \%$ for APO-B whereas in our study it was $59 \%$ for D1S80, $47 \%$ for $\mathrm{D} 17 \mathrm{~S} 30$ and $41 \%$ for APO-B. This difference could be related to the difference in race or ethnic groups of the studied subjects. It may be also explained by a difference in VNTR sequence used or even amplification protocols applied. ${ }^{3}$

Unfortunately, both gene loci (ZP3/SRY) were not informative in our study. Although trying different amplification protocol none of them seemed to be successful. This is consistent with the previous observation of Wang et al. ${ }^{8}$ that such failure could be explained by the difference in GC amount in the amplified VNTR sequence which led to a difference in melting temperature optimal for each reaction. In our work, all patients included received myeloablative regimen. Fourteen patient demonstrated full donor chimerism for samples collected on day 28 following transplantation, which is consistent with Devine et al. ${ }^{17}$ findings that conventional myeloablative regimens typically promote full donor hematopoietic chimerism. ${ }^{17}$

Graft failure with autologous recovery was detected in one patient with acute myeloid leukaemia who died shortly after 45 days of transplantation due to relapse which was consistent with our finding of persistent recipient chimerism. Another case with acute lymphoblastic leukaemia demonstrated split chimerism, which could be explained by incomplete myeloablation pre-treatment (transplantation was done with a positive minimal residual disease result). This is explained by Hans et al. ${ }^{18}$ who stated that donor chimerism in T cell subset occurs later than other cell subsets, especially when transplanted with residual malignant cells which is the case here (having a positive MRD at the time of transplant). ${ }^{18}$

Several methods have been used for detecting chimerism status after allogeneic bone marrow transplantation, we chose the VNTR method as Ugozzoli et al. ${ }^{19}$ demonstrated that VNTR has many advantages over RFLP which include that VNTR required less DNA (approximately 250ng); there was no need for DNA digestion, and VNTR was more rapid and sensitive. VNTR analysis has many advantages as we have listed before and is a good predictor of chimerism status in post-transplantation follow up but sometimes we face difficulties in differentiation between donor and recipient allelic distribution which denote the importance of the use of wider scope of genetic markers. Nowadays, short tandem repeats are considered the standard test for quantitative chimerism analysis ${ }^{20}$ genotyping in parentage testing ${ }^{21}$ and forensic human identity testing. ${ }^{22}$ Many studies compared the precision and efficacy of VNTR in comparison with STR. Mossallam et al. ${ }^{12}$ concluded that there is concordance in chimerism results when they compared both techniques results together. Their sensitivity was almost the same ${ }^{23}$ but STR showed better results in discrimination capacity.VNTR discriminatory power could be potentiated with the use of smaller size VNTR. Unlike STR, VNTR is used as a qualitative or even semi-quantitative test if we constructed a standard curve using serial dilutions of the recipient and donor DNA. We may also use band intensity as an indicator for the degree of donor-recipient DNA concentrations. In spite of the stated advantages of STRs, the cost of the analysis is very high including the instrumentation and the kits which are not applicable in underresourced countries. We, therefore, recommend the VNTR as a preliminary cost-effective tool that can be informative in most of the cases. The number of VNTRs could be further extended to solve cases where there are no informative markers, hence saving more expensive procedures as a second line for selected cases that showed no success with VNTRs.

Some studies have confirmed that chimerism analysis in $\mathrm{T}$ cells 
is more informative for the evaluation of graft-versus-host disease risk than that of whole blood peripheral blood. We could not assess any additional value for $\mathrm{T}$ cell chimerism as only one of our cases showed a disparity between whole blood and $\mathrm{T}$ cell subset chimerism results..$^{24,25}$ This study was initiated with the start of HSCT practice in our hospital and would be further extended on a larger scale.

\section{Conclusion}

VNTRs analysis is a cost-effective method in chimerism detection in most of the cases. D1S80 is the most informative VNTR in our studied population .It is not preferred to use gene loci ZP3 and SRY. The value of subset analysis is yet to be studied on a larger number of patients.

\section{Acknowledgements}

None.

\section{Conflict of interest}

Authors declare that there is no conflict of interest.

\section{References}

1. Gyurkocza B, Rezvani A, Storb RF. Allogeneic hematopoietic cell transplantation: the state of the art. Expert Rev Hematol. 2010;3(3):285-299.

2. Patrick Schlegel, Christian Seitz, Peter Lang, et al. Allogeneic Stem Cell Transplantation. Immunotherapy for Pediatric Malignancies. USA: Springer; 2018:39-64.

3. Sreenan JJ, Pettay JD, Tbakhi A, et al. The use of amplified variable number of tandem repeats (VNTR) in the detection of chimerism following bone marrow transplantation. A comparison with restriction fragment length polymorphism (RFLP) by Southern blotting. Am J Clin Pathol. 1997;107(3):292-298.

4. Khan F, Agarwal A, Agrawal S. Significance of chimerism in hematopoietic stem cell transplantation: new variations on an old theme. Bone Marrow Transplant. 2004;34(1):1-12.

5. Passweg JR, Baldomero H, Bader P, et al. Use of haploidentical stem cell transplantation continues to increase: the 2015 European Society for Blood and Marrow Transplant activity survey report. Bone Marrow Transplant. 2017;52(6):811-817.

6. Knight-Perry J, Miller WP, Orchard PJ, et al. Peripheral Blood Lymphoid and Myeloid Chimerism after Hematopoietic Stem Cell Transplant for Non-Malignant Disorders. Biology of Blood and Marrow Transplantation. 2018;24(3):S309.

7. Kletzel M, Huang W, Olszewski M, et al. Validation of chimerism in pediatric recipients of allogeneic hematopoietic stem cell transplantation (HSCT) a comparison between two methods: real-time PCR (qPCR) vs. variable number tandem repeats PCR (VNTR PCR). Chimerism. 2013;4(1):1-8

8. Wang LJ, Chou P, Gonzalez-Ryan L, et al. Evaluation of mixed hematopoietic chimerism in pediatric patients with leukaemia after allogeneic stem cell transplantation by quantitative PCR analysis of variable number of tandem repeat and testis determination gene. Bone Marrow Transplant. 2002;29(1):51-56.

9. Thiede C. Diagnostic Chimerism Analysis After Allogeneic Stem Cell Transplantation. Am J Pharmacogenomics. 2004;4(3):177-187.

10. Holland MM, Roby RK, Lee DA, et al. DNA Analysis. Handbook of Analytical Therapeutic Drug Monitoring and Toxicology. USA: CRC Press; 2017:35-49.
11. Azmy C, Ayello J, Fabricatore S, et al. Comparison of T \& NK Cell Donor Chimerism \& Hematopoietic Engraftment Following Allogeneic Hematopoietic Stem Cell Transplantation in Pediatric Recipients Receiving Bone Marrow (BM) or Umbilical Cord Blood and/or Human Placental Derived Stem Cells (HPDSC). Biology of Blood and Marrow Transplantation. 2018;24(3):S419-S420.

12. Mossallam GI, Smith AG, McFarland C. Comparison of variable number tandem repeat and short tandem repeat genetic markers for qualitative and quantitative chimerism analysis post allogeneic stem cell transplantation. J Egypt Natl Canc Inst. 2005;17(2):103-113.

13. Gümüş G, Rustamov A, Kadikiran A, et al. D17S30 and TP53 VNTR Loci Polymorphisms in a Turkish Population. Hum Biol. 2004;76(5):785-788.

14. Gécz J. PCR amplification of large VNTR alleles of D17S5 (YNZ22) locusNucleic Acids Res. 1991;19(20):5806.

15. Muniz ES, Plassa F, Amselem S, et al. Molecular analysis of polymorphic loci to study chimerism after allogeneic bone marrow transplantation. Heteroduplex analysis in denaturing gradient gel electrophoresis: a new approach to detecting residual host cells. Transplantation. 1994;57(3):451-456.

16. Stuppia L, Calabrese G, Di Bartolomeo P, et al. Retrospective investigation of hematopoietic chimerism after BMT by PCR amplification of hypervariable DNA regions. Cancer Genet Cytogenet. 1995;85(2):124-128.

17. Devine SM, Adkins DR, Khoury $\mathrm{H}$, et al. Recent advances in allogeneic hematopoietic stem-cell transplantation. J Lab Clin Med. 2003;141(1):7-32.

18. Lee HC, Saliba RM, Rondon G, et al. Mixed T-lymphocyte chimerism after allogeneic hematopoietic transplantation is predictive for relapse of AML/MDS. Biol Blood Marrow Transplant. 2015;21(11):1948-1954.

19. Ugozzoli L, Yam P, Petz LD, et al. Amplification by the polymerase chain reaction of hypervariable regions of the human genome for evaluation of chimerism after bone marrow transplantation. Blood. 1991;77(7):1607-1615.

20. Frankel W, Chan A, Corringham RE, et al. Detection of chimerism and early engraftment after allogeneic peripheral blood stem cell or bone marrow transplantation by short tandem repeats. Am J Hematol. 1996;52(4):281-287.

21. Alford RL, Hammond HA, Coto I, et al. Rapid and efficient resolution of parentage by amplification of short tandem repeats. Am J Hum Genet. 1994;55(1):190-195.

22. Yong T Kim, Hyun Y Heo, Tae S Seo. Advanced Short Tandem Repeat Genotyping for Forensic Human Identification. In: Ho Nam Chang, editor. Emerging Areas in Bioengineering. USA; 2018. p. 509-529.

23. Van Deerlin VM, Leonard DG. Bone marrow engraftment analysis after allogeneic bone marrow transplantation. Clin Lab Med. 2000;20(1):197-225.

24. Clemente I, Goncalo A, Faria C, et al. Relevance of Chimerism Analysis After Allogeneic Stem Cell Transplantation. Transplant Proc. 2017;49(4):890-892.

25. Kricke S, Mhaldien L, Fernandes R, et al. Chimerism Analysis in the Pediatric Setting: Direct PCR from Bone Marrow, Whole Blood, and Cell Fractions. J Mol Diagn. 2018;20(3):381-388.

26. Kamel AM, Mossallam GI, Mahmoud HK, et al. Variable number tandem repeat polymorphism as a tool of chimerism detection in allogeneic stem cell transplantation. J Egypt Nat Cancer Inst. 2002;14(4):275-282.

27. Skowasch K, Schürenkamp M, Rand S. Comparison of population data using 3 AMPFLP systems. Advances in Forensic Haemogenetics. USA: Springer; 1992:75-77. 
28. Ruiz Ada S, Chauffaille Mde L, Alves ST, et al. Prevalence of chimerism after non-myeloablative hematopoietic stem cell transplantation. Sao Paulo Med J. 2009;127(5):251-258.

29. Mukherjee M, Srivastava Akanchha, Kesari A, et al. Analysis of VNTR loci, ApoB 3'HVR and D1S80 in North Indians. IJBT. 2005;4(3):358-362.

30. Zhou Z, Bebeli P, Somers D, et al. Direct amplification of minisatelliteregion DNA with VNTR core sequences in the genus Oryza. Theoretical and Applied Genetics. 1997;95(5):942-949.

31. Rankin TL, Tong ZB, Castle PE, et al. Human ZP3 restores fertility in Zp3 null mice without affecting order-specific sperm binding. Development. 1998;125(13):2415-2424.

32. Erdal ME, Barlas I. Detection of the SRY Gene in a 46, XY Phenotypic Female by the PCR-SSCP Method. Turk J Med Sci. 2000;30(5):501-504.

33. Drobnič K. A new primer set in a SRY gene for sex identification. International Congress Series. 2006;1288:268-270.

34. Settin A, Elsobky E, Hammad A, et al. Rapid Sex Determination Using PCR Technique Compared to Classic Cytogenetics. Int J Health Sci (Qassim). 2008;2(1):49-52. 